\title{
Questioning the 'Anthropos' in the Anthropocene: Is the Anthropocene Anthropocentric?
}

\author{
Rangga Kala Mahaswa ${ }^{1 *}$ and Agung Widhianto ${ }^{2}$ \\ ${ }^{1}$ Faculty of Philosophy, Universitas Gadjah Mada, Jl. Olahraga, Caturtunggal, Depok, \\ Sleman, Yogyakarta 55281, Indonesia \\ ${ }^{2}$ Department of Political Science, Umeå University, SE-901 8 7, Umeå, Sweden
}

\begin{abstract}
The word 'Anthropocene' has been controversial scientific concept, to name a new geological epoch that situates 'Anthropos' or 'Man' as an actor changing geological structure, altering the Earth system, and also making in unpredictable planetary changes. Criticism of the Anthropocene is based on Holocene's formal ratification rather than the Anthropocene findings. In addition, this paper will argue a realism philosophical approach though that the Anthropocene is not merely scientific speculation. This paper provides an ontological justification for humanity's causal power in geological time based on Bhaskar's critical realism and Graham's speculative realism. This ontological turn will be a 'new conceptual ground' to define the Anthropocene without being imprisoned in 'Anthropocentrism' and will contribute to other fields, such as social sciences and humanities, to remake their understanding of the Anthropocene. Therefore, the result will be able to strengthen the Anthropocene ratification indirectly.
\end{abstract}

Keywords: Anthropocentrism, geological epoch, ontological turn, realism, terra incognita.

\section{Introduction}

The cycle of the Earth is facing crisis. In geological terms, an epoch is a midsize section of Earth history. Everything on Earth is witnessing changes significant enough to mark the ending and the beginning of another epoch. The present Earth condition is hard to comprehend its magnitude with the last Earth epoch-Holocene. However, recognizing the most situation today can help us respond to the transition to living a new division of geological time called Anthropocene. The idea of the Anthropocene epoch brings a unique perspective regarding human position through geological deep-time, for example, the discourse of Anthropocentric in the Anthropocene.

Jeremy Devies argues that the Anthropocene is not an anthropocentric concept; this concept is not related to a single essence and inseparable from the rest of nature [1]. Human is not the ontological center of the world because the Anthropocene is still using the results of the work from stratigraphers which determine the formalization of a geological timescale

\footnotetext{
*Corresponding author: rangga.mahaswa@gmail.com
} 
based on the deposition of rock layers globally. Using a geological method of understanding something is beyond political or spiritual thought, for example concept of Gaia in a geological view. While the common sense of Anthropocene tends to draw the end of human civilization, its multiple contradictions, simultaneously frightening and paralyzing, all human beings as a unique species have collectively collaborated in the alteration of geological structure. Davies strives to date the Anthropocene with the most significant impact of human being on earth, from fossil-fueled industrialization in the 1800 s, the Great Acceleration across the postcolonial world in 1945, the rise of global nuclear invention, as well as many other possibilities [1].

The original idea of the Anthropocene is also related to the Russian Vladimir Verdansky in 1926, who defined the Anthropocene as a part of five significant spheres of the Earth system, consisting of Hydrosphere; Lithosphere; Biosphere; and Anthroposphere. Ellis tries to explain how humanity affects the planet rapidly since the control of fire, intensive farming and hunting, colonialization, the Industrial Revolution, and the Great Acceleration. These actions have changed the climate condition, widespread toxic pollution, and mass extinction of species. All of these events are permanently detailed in the rocks as the geological record [2]. It juxtaposes that human being as the primary mover of nature but cannot control their effects continuously. The discourse of the Anthropocene opens a new geological awareness of human fragility as part of deep time. It is because human faces the different view of unknown world in the present and future. By the time Earth departs from a period of relative geological stability, the nascent Anthropocene should be attended by unknown survivors to work strenuously for the 'terra incognita' in the future.

Terra incognita is one of the examples of augmenting human agency as a primary actor of changes in global systems in the discourse of an uncertain future. Anthropocene finds itself in between inspiring awe in the beautiful geo-history while challenging human being to anticipate survival amid tremendous loss or stay motivated to radical transformation changes. Several discourses in Anthropocene are developed in terms of pessimism or optimism concerning the future of the geological time scale. Therefore, this research is only limited concerning criticism of Anthropocentrism in the Anthropocene view based on philosophical approaches, especially ontological realists.

\section{Methods}

As a philosophical research, this philosophy method based on deep-reflection to interpret data by using qualitative method and literature review [3]. Several collected works of literature are interpreted further as a 'higher-order' reading as a philosophical method based on formulating a hypothesis, collecting data, comparing-eliminating data, analyzing data, and philosophizing data [4]. This paper will address the problem of what the Anthropocene means for a common understanding of how human relate to nature. Therefore, this paper will argue that understanding human-nature relations in the Anthropocene term is based on not only scientific approach, but also a realist approach to evaluate the Anthropocentric in the Anthropocene.

\section{Results and discussion}

\subsection{Anthropos in Holocene}

Humans included in the term Anthropocene are considered problematic notion because it is not in line with the general geological investigation that maintains its natural objectivity 
and must be separated from the human condition. It is reasonable because geology is linked to the objectivity of material things rather than the subjectivity of human being. Holocene (entirely recent) as a formal epoch in geology was proposed by geologists to counterargument that human is the center of life. The Holocene has three primary points of evidence, namely the end of the last glacial, the emergence of humans, and the rise of a new civilization [5]. The range of the Holocene geological period lasts around $11700 \mathrm{yr}$ when summer becomes longer and departure from ice age $[6,7]$. This epoch also resulted in the extinction of megafauna and climate change at the end of the ice age. It implies that the current interglacial is different from its Pleistocene counterpart. The changes in conditions on Earth are considered more 'stable' than before. This so-called 'balance' condition enables Homo Sapiens to build a new agricultural system that led them to a great civilization. Therefore, the Holocene has indirectly rejected the Anthropocene thesis. Anthropocene is no longer needed since humans are also included in the Holocene historical explanation.

Paul Crutzen, in 2000, introduced the term Anthropocene into geological discourse [8]. However, the narrative itself emerged around the 19th century when Antonio Stoppani (1824-1891) explained his thesis on the growing scale of anthropogenic activities and impacts on the geological structure that primarily pertains to the environment [9]. Geology was a theological discourse in terms of the doctrine of God, humans, Earth, and it was called the "Anthropozoic era." It is not surprising that in the present day, all discussion related to human beings within the geological discourse is limited. It is due to some geologists who believe that geology is purely involved with the natural past and irrelevant to human activities. For this reason, the International Union of Geological Sciences (IUGS) proposes the Holocene as the current geological epoch and formally becomes the latest geological time scale [10].

The Holocene is unavoidable because geological scientists continue to provide more scientific evidence based on the most recent findings of new subdivisions in the Holocene [11]. This evidence leads actively to Mawmluh Cave, Meghalaya, northeast India, in 2018 [12]. Meghalayan evidence occurred around $4200 \mathrm{yr}$ ago, during which there was a 200-yr of global drought that occurred and impacted human civilizations in Greece, Syria, Egypt, Canaan, Mesopotamia, the Indus Valley, and the Yangtze River Valley. Geologists assumed that Meghalayan stopped in 1950, but later recanted it in the next subdivision (age or stage) [13]. The International Commission officially ratified the Meghalayan age on Stratigraphy along with Greenlandian (11 700 to 8 326) yr ago and Northgrippian (8 326 to 4200 ) yr ago [14]. It meant the Anthropocene's assumptions at the beginning of 1950 was unacceptable.

LeCain draws a critical view on the emerging neo-materialist theory to suggest a radically different approach that human has been created by and with a robust material environment [15]. It offers a more critical view that the Anthropocene is the misleading anthropocentrism rather than explaining the real geological condition [16]. The Anthropocene might seem an objective perspective like other disciplines, yet it cannot deny that there is a species-based element which solely concerns the wellbeing of humanity. As an epiphany moment in shaping the planetary climate, the Anthropocene is not merely because of humans but also regarding nature and later affected the realm of humans [16]. On the other hand, the central paradox of the Anthropocene narrative is meant to denaturalize the nature-related cause of all human-being activities. In the next phase, naturalization is derived from the ability of human that evolve from the first control of fire to create the Great Acceleration.

Lastly, the Anthropocene narrative could be seen as illogical because since humanity can transform the Earth, everything belongs to the domain of human affairs. It is implicitly constructed to reconcile the natural and the social condition in reality, and this notion could 
be false thinking because human activities extend and yet condensed into society. Like many social-humanities scientists with their anti-social tendencies, they are attracted by the idea of Anthropos as a center of new geological time scale (constructive or destructive), which develop to specific humanist approaches [17-19]. Finally, the notion of intervention can be used in the Anthropocene narrative that bears the idea, analytically and not yet completed, to point out humans as the center of whole geological shifting. Human is the only particular effect of collectiveness causation and on the Earth's surface.

\subsection{Anthropocentrism and Anthropocene}

Evidently, humanity's geological role in the primary key theme in reviving further discussion about the human position globally [20]. The Anthropocene interpretation is a dual perspective between geological and non-geological findings. Several views can be used to ensure the validity of Anthropocene thesis in terms of geological understanding (stratigraphic evidence), biology (anthropogenic changes in the biosphere), social (an intersection of social processes, society, and history) and culture (creative understanding, reaction speculative, and cultural representation former position) [21]. Moreover, this research opens a new perspective to provoke that philosophical perspective can complement the understanding of the Anthropocene thesis in a unique way. The Anthropocene is not anthropocentric because it redefines what it means to be human.

Anthropos or human as a strong candidate to Anthropocene evidence is resulted by research-based on several recent geological data and 'golden spike' prediction: i) First Human Intervention, ii) Industrial Revolution, and iii) The Great Acceleration [22]. To establish human position, the phases of first human intervention could be divided into; the discovery of fire, the emergence of new techniques, hunting and gathering, domestication of animals and plants, and the spirit of new world exploration. The Industrial Revolution also had a significant impact on the acceleration of the use of fossil fuels based on socialprogressive change. After the 1950s, 'The Great Acceleration,' with its turning point, triggered a massive global transformation because of increasing anthropogenic activities. All of this evidence is working to develop a philosophical standpoint: by contradicting the Anthropos status and then strengthening a new perspective to defend Anthropos in Anthropocene without adopting the Anthropocentrism perspective.

Some contradictory arguments for the Anthropocene are directed towards the inclusion of the term Anthropos (human). It is a contradiction because geology, in general, is the study of Earth's material in its entirety, from its origin, structure, dynamics, and physical material of Earth. Anthropos tends to be an ambiguous or even speculative path of geological and prompted a problem in the ratification process of the Anthropocene. Furthermore, this notion accompanies a representation of human arrogance. In the past, geology probably placed humanity as the highest agent, the ruler, to control everything based on the Scriptures or other theological perspectives. Then, is it true that Anthropocene can be identified as Anthropocentrism in geological discourse? The answer is speculative probability. In short, Anthropocene and Anthropocentrism certainly signified different stance of understanding of the world.

Anthropocentrism understands human as the highest reality than other or the notion of reality which originates solely and exclusively because of the human's existence [23]. In other words, the reality is constructed based on human subjectivity. Anthropocentrism is also grounded in teleological explanation as a center of everything in terms of structures (descriptively) or values (normatively). Amid the spirit of modern society, human supremacy attacked superstition or dogma and indirectly prompted the birth of Anthropocentrism, which prospered humanism; human as the most intelligent being in the universe. Further example, Anthropocentrism types are divided into three points: i) Cosmic 
(human-center universe), Axiology (values-based of human interests), and Epistemic (inevitable human perspective) [24]. Nature has been the second part of human being or merely instrumental as well as assuming a meaningful role in making value-usage. This research exactly declines these notions, because Anthropocentrism's dogmas also promote another problem, namely the existential anxiety [25]. Today, human being always confronts capricious conditions. Everything is limited to human perspective. Humanity is incapable of surviving alone even by sacrificing 'the others. Philosophically speaking, Anthropocentrism itself has a problem related to its objectivity existence.

Humans are no longer considered the center of everything after the enlightenment of the scientific world. The enlightenment did both: humans were the center of the universe and all meaning, but humans were also part animal-a result of evolution. Several paradigm shifts began during the emergence of the heliocentric model, the Darwinian theory of evolution, and the culmination of biocentrism. Anthropocentrism is only the commitment to ontological and epistemological beliefs that elevate the position of humankind above all things. The best claim to maintain Anthropocentrism in the realm of the Anthropocene epoch is only to place humans as the antecedent of the existence to nonhuman by using 'weak anthropocentrism' rather than 'strong anthropocentrism.' [26]. Weak Anthropocentrism still accepts human being from the point of view, then the world is fundamentally structured based on human action but also acknowledges the importance of considering non-human value insofar as it supports human prosperity. It means that Anthropocene should never be claimed as Anthropocentrism because everything that is human-made cannot be controlled completely. Therefore, Anthropocene without Anthropos (human) is impossible, and on the one hand, it inspires alternative ideas besides Anthropocene, for example, Moore's Capitalocene, Haraway's Chthulucene, Bounneuil and Fressos's Anglocene, and Swyngedouw's Oliganthropocene.

\subsection{Realist Anthropocene}

This research highlights a realist approach as an ontological realism standing point to explain how human activity (anthropogenic) has affected geological changes. Realism is a mind-independent world metaphysical view [23, 27]. Realism in Anthropocene is possible if and only if humans are no longer pure-human-subjects but geological objects, which means aspects of humanity must be omitted first. This assumption is similar to the justification of the sociological domain that human being can be understood as objective facts. The causal power of the Anthropocene is not based on an individual personal subjectivity but as an objective collectivistic, that is inclusive with non-human as other causal powers [28]. Human should be drawn like other geological objects. In addition, causal power is limited to change, create, and control things in terms of the Anthropocene epoch. Therefore, the understanding of the Anthropocene perspective appears after the exchange of anthropogenic activity.

To defend Anthropos in the Anthropocene, this article then develops several arguments, such as:

First, if humans as the object or geological material, then Anthropocene can reduce or decenter humans from the Anthropocentrism perspective in so far as the basis date measurement. Nevertheless, human artefacts are creating a new geological layer empirically known as techno-fossils, marked by the evolution and diversification of technofossils geologically by using the techno-stratigraphy approach [29, 30]. As causal power, humans are considered as different degrees of geological objects than others.

Second, the Anthropocene view should separate fact from value. Anthropogenic activities and human impacts in the specified geological timeline are objective facts and deprived of value-depend-subjectivity. Value also has several philosophical problems from 
domains of subjectivity and objectivity. Europeans during the Industrial Revolution era were a group of different people compared to what we know as rural people today because, in terms of values or valuation, everyone is considered a unique being who must be understood in their own time and space. Thus, both cannot be considered as the antecedent to an occurrence, or one group is responsible for the actions of that are done towards nature, and vice versa.

Third, the awareness of the Anthropocene did not arise during the Industrial Revolution when people used fossil fuels widely. People at that time tended to be unconcerned using fossil fuels on a large-mass scale. In regards to the socio-epistemological perspective, this is not a big problem to use fossil fuels because human duty was to conquer and control Earth's energy at that time. However, it would be different when climate change emerged in the last few decades, and people became more aware of the negative impacts of fossil fuel on the environment. Thus, the causality-power of human in the 19th century still continues until today, despite the inexistence of our predecessors. Therefore, it proves that humans still unable to retain control of everything, not even their anthropogenic effect afterward.

Fourth, this research is based on the ontological conviction that what humans did in the past (e.g., produce carbon gas emissions) cannot precisely be separated from other nonhuman factors. Thus, Anthropocentrism will decline by itself. Anthropocene must be consistent with geological investigation rather than being trapped solely for blaming human responsibility related to crises on Earth. It means the geological facts are different from social circumstances. The present Anthropocene evidence only refers to Global Standard Stratigraphic Age (GSSA) and Global Stratotype Section and Point (GSSP) to cover rigorous and scientific geological findings.

Fifth, terra incognita is a part of the Anthropocene justification concerning the latter's future. It posits the Earth as an unknown world for the sake of prediction due to the forthcoming planetary instability. It means that human cannot be understood as the exclusive dominating force. Inadequate condition, human is only part of geological agent. Humans can be thought of as like dinosaurs in the Mesozoic era; the last population of 7.6 billion people today can vanish at any time without certainty time and space. Therefore, the sixth extinction is one of terra incognita conditions to eliminate humanity and change the next geological object if the Earth-object still exists.

Based on the last fifth arguments, the Anthropocene is aligned with other formal geological epochs, but it considers Anthropos from a different geological object degree [31]. To explain this concept, this research is inspired by Bhaskar's notion (Critical Realism) [32] and Harman's idea (Object-Oriented-Philosophy) regarding speculative realism [33, 34]. Critical realism is a philosophy of science-based on several ontological realist principles. Object oriented philosophy is to reject the human existence meaning over the non-human object privilege. First, as a philosophical dimension, Anthropocene has a complicated ontological notion of seeing human as a center of everything. Indeed, Anthropocene shifts the idea of human power supremacy to the futility of humans in terra incognito situations. Anthropocene enforces the discourse of climate change and global warming to humans as these are procured by the lifestyle of the society on Earth. However, both conditions become real yet enigmatic to human, including how human power can completely mitigate the impacts of climate change or global warming. In short, Table 1 understands the status of a human being in the Anthropocene epoch through the realist investigation $[31,32]$.

Based on Table 1, understanding humans in the Anthropocene term should be treated like the geological subject and not as human subjects directly. As a unique object, humanity cannot be utterly generalized to other objects (human or non-human), but each object has its level of autonomy that cannot be reduced [31]. Every single object can explore or cause occurrences. Geology studies object inbound by a specific time and space horizon. Human 
artifacts can be traced on Earth's surface or recorded in rocks. It means that in the subsequent of the anthropogenic event, humans become social objects. The moment geology interferes, geologists can discover the human-trace in techno-sphere or plasticsedimentation.

Table 1. Human in the realist of Anthropocene view

\begin{tabular}{|c|c|}
\hline Quality of objects & Autonomy and Uniqueness \\
\hline $\begin{array}{l}\text { Object are not fully defined by their relationship } \\
\text { with other objects, but have a degree of } \\
\text { autonomy, and some object is more autonomous } \\
\text { than others. It means objects have the ability to } \\
\text { act and explore their fullest potential. }\end{array}$ & $\begin{array}{l}\text { All objects are ends in themselves; Objects are } \\
\text { irreducible and non-substitutable; All objects are } \\
\text { unique; Object discloses in a specific time and } \\
\text { places horizon. }\end{array}$ \\
\hline \multicolumn{2}{|c|}{$\begin{array}{l}\text { Human and human-made objects are not fully embedded/dependent in non-human and non-man-made } \\
\text { objects }\end{array}$} \\
\hline \multicolumn{2}{|c|}{ Ontology } \\
\hline $\begin{array}{l}\text { Things and materials have causal powers } \\
\text { independent of human agency: their realization is } \\
\text { contingent. For example: Gravity (Natural } \\
\text { necessity) or Climate Change (Human } \\
\text { intervention) }\end{array}$ & $\begin{array}{l}\text { Human has pre-existence of social structures } \\
\text { (transformed and reproduced by social-actors) }\end{array}$ \\
\hline $\begin{array}{l}\text { The intransitive dimension of Anthropocene: } \\
\text { Stratification of the world into a different level of } \\
\text { 'ontological time.' }\end{array}$ & $\begin{array}{l}\text { A human agency with intentions: reasons as real } \\
\text { causes }\end{array}$ \\
\hline $\begin{array}{l}\text { The existence of natural necessity: secretion of } \\
\text { causal powers through generative mechanisms } \\
\text { and enduring tendencies in geological time scale. }\end{array}$ & $\begin{array}{l}\text { The continuous process of structuration between } \\
\text { structures and agency }\end{array}$ \\
\hline Epistemology & Methodology \\
\hline Anthropocene is an ongoing process & Process of retroduction: a posteriori reasoning \\
\hline $\begin{array}{l}\text { Transitive dimension of Anthropocene: } \\
\text { scientific/social (re)production of knowledge }\end{array}$ & $\begin{array}{l}\text { Possibility of experimentation (GSSP) and the } \\
\text { use of postulated entities and analogies/time } \\
\text { approximate (GSSA) }\end{array}$ \\
\hline $\begin{array}{l}\text { The search for golden spike in Anthropocene: } \\
\text { explanation but not a prediction. }\end{array}$ & Practice: theoretical and empirical research \\
\hline
\end{tabular}

Ontologically speaking, the vision of realizing an Anthropocene realist is to consider that the geological worldview consists of existing independent structures and mechanisms, with their own domain. Humans, as a part of geological reality, include certain emergent levels, complexity, and freedom within every single entity, thus the similitude between humans and other material objects, with the former having different causal power. Structuration in a social structure has been continuously reproduced and transformed by humanity throughout the geological timeline. The real causal power dimension of human being is intensively situated in reason; reason acts autonomously with unique causality. However, the center of human reason is still limited to define what human is. The modernist view cannot explain further about the Anthropocene, because it tends to separate between human and non-human. Therefore, critical realism evaluates this notion through intransitive dimension (reality) and transitive dimension (social-constructed) that reason is not everything to explain reality as an independent essence. The Anthropocene intransitive dimension follows the stratification of the world into different levels of the geological deeptime scale. Anthropocene emerges via generative mechanisms and natural tendencies in understanding human concerning the new epoch in geology without being branded as anthropocentrism.

Epistemologically speaking, Anthropocene is an epistemic process that the structure of the Anthropocene itself is always added by anthropogenic events and the search for the Anthropocene golden spike. As transitive critical realism, understanding of Anthropocene 
reality is obtained through the re-production of knowledge, both through the scientificexplanation and social-construction. The by-product of knowledge places an explanatory position rather a mere prediction or speculation of Anthropocene in the future [35]. Therefore, empirical (a posteriori) research practice develops the process of retroduction reasoning. Therefore, it strengthens Anthropocene as a form of sophisticated Anthropocentrism because the goal of experiments is used to construct the representation of geological and estimated time.

\section{Conclusions}

This research concludes that the term Anthropocene in realism will not be problematic despite its involvement with humans in geological discourse. It is because the issue of 'Anthropos' will not affect the work of geologists regarding objectivity findings. Although the Anthropocene seems ambiguous and speculative because it places humans and their elements in it, it does not matter regarding its ratification. This research also completes a new philosophical framework in terms of quality of the object (autonomy-uniqueness), stratified reality, transitive-intransitive dimension, and causal power of geological actors. Finally, the future Anthropocene discussion will incorporate the politics of geology and remove the entire discourse from the gray area.

\section{References}

1. J. Davies, The Birth of the Anthropocene, California: UC Press (2016). https://www.ucpress.edu/book/9780520289987/the-birth-of-the-anthropocene

2. E.C. Ellis, Anthropocene: A Very Short Introduction, UK: Oxford University Press (2018). $\quad$ https://global.oup.com/academic/product/anthropocene-a-very-shortintroduction-9780198792987?cc=id\&lang=en\&

3. H. Snyder, Journal of Business Research, 104:333-339(2019). https://www.sciencedirect.com/science/article/pii/S0148296319304564

4. J. Dever, What is philosophical methodology? In: The Oxford Handbook of

Philosophical Methodology, H. Cappelen, T. Gendler, J.P. Hawthorne (Eds.). UK:

Oxford University Press (2016).

https://www.oxfordhandbooks.com/view/10.1093/oxfordhb/9780199668779.001.0001/o xfordhb-9780199668779-e-34\#oxfordhb-9780199668779-e-34-div1-3

5. R.V. Davis, Earth Sci. Hist., 30:63-84(2011). https://earthscienceshistory.org/doi/abs/10.17704/eshi.30.1.p8327x7042g3q989

6. D. Dumanoski, The End of the Long Summer: Why We Must Remake Our Civilization to Survive on a Volatile Earth, (New York: Three Rivers Press, 2009). https://www.amazon.com/End-Long-Summer-Civilization-Volatile/dp/0307396096

7. B. Fagan, The Long Summer: How Climate Changed Civilization, (Cambridge: Basic Books, 2004). https://www.nhbs.com/the-long-summer-book

8. P.J. Crutzen, The Anthropocene. In: Earth System Science in the Anthropocene. E. Ehlers, T. Krafft (Eds). Berlin, Heidelberg: Springer (2006), https://link.springer.com/chapter/10.1007/3-540-26590-2_3

9. E. Luciano, The theory of the Anthropocene: Inquiry into the 'age of Anthropos' between natural sciences and environmental humanities, [Thesis] Environment and Natural Resources, Faculty of Social and Human Sciences School of Social Sciences University of Iceland, Iceland (2018).

https://www.academia.edu/download/57103125/Eugenio_Luciano_MA_Thesis.pdf 
10. T.J. Braje, Journal of Archaeological Research, 23,4:369-396(2015). http://www.jstor.org/stable/10.2307/43956793

11. M. Maslin, S. Lewis, New Scientist, 239,3188:24-25(2018). https://www.sciencedirect.com/science/article/abs/pii/S0262407918313484

12. J. Amos, Welcome to the Meghalayan Age - a new phase in history, BBC Science Correspondent, 18 July 2018, [Online] dari https://www.bbc.com/news/scienceenvironment-44868527 (2018). [Accessed on 2 July 2019].

13. J. Unkelbach, K. Kashima, D. Enters, C. Dulamsuren, G. Punsalpaamuu, H. Behling,

Palaeogeography, Palaeoclimatology, Palaeoecology, 530:1-14(2019). https://www.sciencedirect.com/science/article/abs/pii/S0031018219301300

14. C.M. Silva, G. Arbilla, R. Soares, W. Machado, Rev. Virtual Quim., 10,6:16481658(2018). [in Portugease] http://rvq.sbq.org.br https://www.researchgate.net/publication/330641355_The_new_Meghalayan_Age_Wha t does it Imply for the Anthropocene Age

15. T. LeCain, International Journal for History, Culture and Modernity, 3,1:1-28(2015). https://www.history-culture-modernity.org/articles/10.18352/hcm.474/

16. A. Malm, A. Hornborg, The Anthropocene Review, 1,1:62-69(2014). https://journals.sagepub.com/doi/abs/10.1177/2053019613516291

17. P. Alberts, Angelaki: Journal of the Theoretical Humanities 16:5-17(2011). https://www.tandfonline.com/doi/abs/10.1080/0969725X.2011.641341

18. G. Palsson, B. Szerszynski, S. Sörlin, J. Marks, B. Avril, C. Crumley, et al., Environmental Science and Policy, 28:3-13(2013). https://www.sciencedirect.com/science/article/abs/pii/S1462901112002079

19. B. Szerszynski, Oxford Literary Review, 34:165-184(2012). https://www.euppublishing.com/doi/abs/10.3366/olr.2012.0040

20. Dalby, S. The Anthropocene Review, 3(1), 33-51(2016). https://journals.sagepub.com/doi/abs/10.1177/2053019615618681

21. T. Toivanen, K. Lummaa, A. Majava, P. Järvensivu, V. Lähde, T. Vaden, et al., The Anthropocene Review, 4,3:183-198(2017). https://journals.sagepub.com/doi/abs/10.1177/2053019617738099

22. S.L. Lewis, M.A. Maslin, Nature, 519,7542:171-180(2015). https://www.nature.com/articles/nature14258

23. P. Butchvarov, Anthropocentrism in Philosophy, Berlin: De Gruyter (2015). https://www.amazon.com/Anthropocentrism-Philosophy-Eide-PanayotButchvarov/dp/1614517924

24. S.S. Cerkvenik, Non-humanism, [Online] http://web.colby.edu/humanslashnature/2015/11/15/non-humanism/ (2015). [Accessed on 2 July 2019].

25. D. Chernilo, European Journal of Social Theory, 20,1:44-60(2017). https://journals.sagepub.com/doi/abs/10.1177/1368431016651874

26. J. Beever, Anthropocentrism in the Anthropocene, In: Encyclopedia of the Anthropocene, Dominick A. DellaSala dan Michael I. Goldstein (Eds.). Oxford, Waltham MA: Elsevier (2018), p. 39-44. https://www.elsevier.com/books/encyclopedia-of-the-anthropocene/dellasala/978-0-12809665-9

27. M.J. Loux, T.M. Crisp, Metaphysics: A contemporary introduction. UK: Taylor \& Francis (2017). https://www.taylorfrancis.com/books/9781315637242

28. G. Dürbeck, C. Schaumann, H. Sullivan, Ecozon, 6,1:118-136(2015). http://ecozona.eu/article/view/642 
29. J. Zalasiewicz, M. Williams, C.N. Waters, A.D. Barnosky, P.K. Haff, The Anthropocene Review, 1,1:34-43(2014). https://journals.sagepub.com/doi/abs/10.1177/2053019613514953

30. J. Zalasiewicz, C.N. Waters, M. Williams, C.P. Summerhayes, The Anthropocene as a Geological Time Unit: A Guide to the Scientific Evidence and Current Debate. UK: Cambridge University Press (2019). https://books.google.co.id/books?hl=id\&lr=\&id=U7-GDwAAQBAJ\&o

31. P. Heikkurinen, J. Rinkinen, T. Järvensivu, K. Wilén, T. Ruuska, Journal of Cleaner Production, 113:705-714(2016).

https://www.sciencedirect.com/science/article/pii/S0959652615018399

32. M. Archer, R. Bhaskar, A. Collier, T. Lawson, A. Norrie, Critical realism: Essential readings. UK: Routledge (2013). https://books.google.co.id/books?hl=en\&lr=\&id=wz6N9uBpnYC\&oi

33. G. Harman, Tool-being: Heidegger and the metaphysics of objects. Chicago: Open Court Publishing (2011). https://books.google.co.id/books?id=Hz6PLV_1R-QC\&dq

34. G. Harman, Prince of networks: Bruno Latour and metaphysics. Prahran: Re.press (2009). https://books.google.co.id/books?id=b7YEnwEACAAJ\&dq

35. C.N. Waters, I.J. Fairchild, F.M.G. McCarthy, C.S.M. Turney, J. Zalasiewicz, M. Williams, Geology Today, 34,5:182-187(2018).

https://onlinelibrary.wiley.com/doi/abs/10.1111/gto.12245 